\title{
Un estudio preliminar sobre las fuentes del episodio de la locura de Orlando en el marco de la poética ariostesca y de la cultura humanista y renacentista
}

\author{
Sabina LONGHITANO PIAZZA \\ Universidad Nacional Autónoma de México
}

Establecer y analizar cómo los autores utilizan sus fuentes textuales es siempre un asunto complejo. Esto vale en general para cualquier escritor europeo, especialmente los anteriores al Romanticismo, donde la relación entre un autor y sus fuentes textuales cambió para siempre, al sustituir las nociones clásicas y humanistas de imitación y emulación con la de la originalidad como el criterio estético fundamental. Y vale a fortiori para los autores del Renacimiento, educados según el modelo humanista, que marcó una nueva relación con la antigüedad clásica, con un enfoque crítico y filológico que se opuso tajantemente a la interpretación medieval cristiana, alegórica, que buscaba relaciones de continuidad con el mundo clásico. Ésta es la razón del peculiar tratamiento de las fuentes clásicas por parte de los autores del Renacimiento, quienes las utilizan para revitalizar géneros medievales, y en particular el poema caballeresco. Desde esta perspectiva presento los resultados de un estudio preliminar sobre las fuentes del episodio central del Orlando Furioso de Ludovico Ariosto: el episodio de la locura de Orlando.

PALABRAS ClAVE: análisis de fuentes literarias, humanismo, cultura del Renacimiento, imitación, eulación, Ariosto, Orlando Furioso.

Assessing and analyzing the use that authors make of their textual sources is a complex matter. If this is generally true regarding any European writer, especially those prior to the Romantic movement — which changed once for all the relationship between authors and their textual sources by substituting the classical-humanist notions of imitation and emulation with the notion of originality as an aesthetic criterion - , this is particularly important in a discussion of Renaissance authors. The new, critical-philological approach to the classical world promoted by the Humanist movement constituted the basis of education during the Renaissance, in strong opposition to the medieval interpretation of the classical inheritance as maintaining continuity with the Christian world. This is why Renaissance authors have a peculiar way of treating the classical sources, using them to revitalize medieval genres, in particular the chivalric poem. It is from this point of view that I present the results of a preliminary study on the sources of the central episode of Ludovico Ariosto's Orlando Furioso: Orlando's Frenzy.

KEY WORDS: Literary source analysis, Humanism, Renaissance culture, imitation, emulation, Ariosto, Orlando Furioso. 
En años recientes, el análisis de las fuentes de Ariosto ha sido ampliamente problematizado al poner en relación las prácticas filológicas tradicionales de búsqueda de fuentes textuales con un marco de referencia constituido por el conjunto cultural de la sociedad renacentista del principio del siglo XVI —el público de Ariosto—y los debates literarios de la época: en general, con la rica y refinada cultura humanista en la que Ariosto estaba sumergido, y en particular con la teoría de la imitación y la Questione della lingua, que planteaba el problema de una única lengua literaria para un país que no tenía una realidad histórico-política. Es en este campo que se coloca este estudio preliminar que se propone presentar un paradigma crítico complejo para después aplicarlo al análisis de las fuentes de un episodio específico del Furioso.

El primer filólogo que dedicó un trabajo orgánico a las fuentes del Furioso fue Pio Rájna (1900), a finales del siglo XIX: ${ }^{1}$ producto del positivismo, su trabajo, a pesar de su enorme erudición, detalle y utilidad, es "absurdo en sus conclusiones" (Binni, 1968: 211): el Furioso es inferior al Innamorato porque tiene una escasa capacidad de invención de hechos y tramas externas, y depende mucho más de una hábil mezcla de fuentes. Además, el afán de Rájna era el de presentar una imagen de Ariosto más ragionatore que fantástico, ${ }^{2}$ menos creativo que Boiardo.

La reacción de la crítica no se hizo esperar ya en tiempos contemporáneos a Rájna. En efecto, Ariosto no compite con Boiardo en cuanto a invención de historias nuevas:

[...] de la misma manera en que un Atlas le alcanza para conocer todas las tierras exploradas, viajando con la fantasía y sin arriesgar su vida, así las historias ya escritas y los mundos ya descritos son suficientes para dibujar su nuevo atlas poético, en el cual los lugares comunes, las situaciones convencionales de la tradición literaria, los tópoi se regeneran a tal punto que hacen olvidar aquella "cadena de las formas anteriores" (Rájna) que la solución ariostesca presupone (Borsellino, 1973: 102).

Resumiendo el debate entre el positivista Rájna y el idealista Croce, Cesare Segre, en su fundamental edición del Furioso (1976: 418), observa que la crítica literaria moderna está especialmente interesada en encontrar las fuentes estilísticas, las que determinan la forma del poema en cuestión, definiéndolas como "fuentes formales". Por su parte, Walter Binni (1968: 214-216) considera que la armonía del Furioso es una armonía dinámica, resultado del encuentro entre la poética renacentista y la poética personal de Ariosto, no sólo en términos estilísticos y formales, sino también con respecto a un conjunto orgánico de ideas y visiones del mundo, exigencias y expectativas estéticas.

Nota: Todas las traducciones de los críticos citados son de la autora.

${ }^{1}$ Para una reseña de las críticas sobre la obra de Rájna, $c f$. Segre, 1990a.

${ }^{2}$ Con base en la dicotomía romántica entre el pensamiento racional (ragionatore) y la creatividad (fantastico) y, como si el primero excluyese o limitase a la segunda, y viceversa. 
La materia del Orlando furioso es la misma de los textos caballerescos y amorosos de la tradición francesa épica y de aventuras, que circulaban abundantemente en la sociedad de Ferrara. Ya en el Orlando innamorato de Matteo Maria Boiardo, que constituye el antecedente inmediato (y de hecho la occasione) del Furioso, el esquema fundamental, basado en la fusión de la épica carolingia con los romances bretones, se entrelazaba con temas de otras fuentes vernáculas, desde las locales, pertenecientes a la tradición franco-véneta, difundida en la llanura padana, hasta las de proveniencia germánica; pero la verdadera novedad — que se configura como una inevitable aportación de la cultura humanista - es la fuerte presencia de fuentes clásicas, especialmente la Eneida.

El resultado fue el de revitalizar la materia caballeresca y transformarla en un "territorio franco" (Borsellino, 1973: 100) en el marco de la codificación de los géneros, en un espacio donde confluyen y se entrelazan fuentes distintas. Esto es posible, ya en el Innamorato y a fortiori en el Furioso, por el potencial creativo inherente al género caballeresco, pero también por las capacidades receptivas e interpretativas del público, muy acostumbrado no sólo a reconocer los núcleos constantes de este repertorio, sino también a apreciar las novedades, las adaptaciones narrativas a nivel culto y popular.

Un término feliz utilizado por la crítica actual con respecto a los tres grandes poetas de Ferrara, Boiardo, Ariosto y Tasso, es “comprometer a los clásicos" (compromising the classics, Looney, 1996), que implica "cómo ciertas fuentes conjugan las tradiciones clásicas y medievales y cómo ciertas otras expresan las categorías retóricas de invención, estilo y disposición" (Looney, 1996: 42-43). La rígida separación operada por Rájna entre fuentes clásicas, asociadas con alusiones verbales y estilísticas, y fuentes medievales, reserva de temas e imágenes, no toma en cuenta la fluidez de la tradición de los textos y la relación que tanto la Edad Media como - de manera muy distinta - el Renacimiento tuvieron con el mundo clásico, por lo que la división entre fuentes directas e indirectas se hace mucho menos tajante. En respuesta a esta categorización estática, Ariosto y también Boiardo y Tasso "comprometían" a los modelos clásicos "incorporándolos en las estructuras narrativas de los poemas vernáculos” (Looney, 1996: 14-15). Así, los poetas superaban, de alguna manera, la distinción entre modelos clásicos y medievales en la construcción de su narración. "Comprometer a los clásicos" significa entonces muchas cosas: la mezcla de fuentes clásicas y medievales, el hecho de que determinadas fuentes resalten más que otras en determinados episodios, las alusiones presentes en el texto y, last but not least, la cultura del medio ambiente de recepción de la obra que implica el reconocimiento de las fuentes por parte del lector y la apreciación del tratamiento, uso y valor comunicativo que el autor quiso atribuir a una u otra fuente.

El repertorio temático del Furioso es aún más amplio y variado que el del Innamorato.

Ariosto retoma la materia de los poemas y novelas caballerescas medievales de Francia y también la de sus adaptaciones italianas como I Reali di Francia de Andrea 
Barberino ${ }^{3}$ y los cantares contemporáneos en volgare del si ${ }^{4}$ Ariosto integra esta materia con la de otras fuentes: desde la tradición de los cuentos (no sólo el Decameron de Boccaccio, sino un gran acervo de cuentos orientales y occidentales, anónimos o de autor, escritos o de tradición oral que circulaban en el Renacimiento) hasta la literatura de viaje, como el Millón de Marco Polo, y las enciclopedias, como el Dittamondo de Fazio degli Uberti; y finalmente tiene muy presente la tradición poética ya identificada y canonizada como "italiana": 5 Dante (Segre, 1966), Petrarca y los poetas del Stil Novo.

Las fuentes clásicas identificadas van desde los poemas homéricos (en traducción latina), la Eneida de Virgilio, las Metamorfosis y las Heroidas de Ovidio (Cabani, 2008; Ruggiero, 2008), la Farsalia de Lucano, la Tebaida de Estacio, la obra de Horacio, de Catulo y de los elegíacos latinos Tibulo y Propercio; los historiadores Valerio Máximo y Justino, el Asno de oro de Apuleyo y las Sátiras Menipeas (Mac Carthy, 2009), además de las antiguas enciclopedias, como la Naturalis Historia de Plinio el Viejo, y tratados como la Corographia de Pomponio Mela y la Geografía de Estrabón, la Introducción a la geografía de Claudio Tolomeo y quizá los Colectanea de Solino, las Vidas de los filósofos de Diógenes Laercio y las Vidas paralelas de Plutarco (Borsellino, 1973: 100-101).

Sin embargo, toda la cultura clásica y medieval presente en el poema es filtrada a través del lente humanista. Esto, según críticos modernos, constituye la clave para poder entender la relación del poeta con sus fuentes, el uso que hace de ellas, el significado que cada una de ellas tiene dentro de la economía del poema, por un lado, y con respecto a sus lectores ideales, por el otro. Entre las fuentes textuales y temáticas humanistas han sido identificadas las Intercoenales de Leon Battista Alberti (Segre, 1965), el Encomion Morias y el De copia verborum de Erasmo (Borsellino, 1973: 101; Segre, 1990b), la Arcadia de Sannazaro (Gulizia, 2008), los neoplatónicos Pico y Ficino, los humanistas latinos Valla y Bruni (Forni, 2006). Sin embargo, el papel de la influencia de autores humanistas y renacentistas se tiene que colocar en el marco de la poética de la imitación: no se trata sólo de fuentes textuales o temáticas, sino al mismo tiempo de fuentes estilísticas que elaboran y filtran toda la cultura anterior, lo que implica decisiones lingüísticas, narratológicas, estructurales, se configura como inter-

${ }^{3}$ I Reali di Francia es una recopilación en prosa de leyendas sobre Carlos Magno y Roldán escrita por Andrea da Barberino, escritor y "cuentacuentos" florentino activo al comienzo del siglo XV.

${ }^{4}$ Según la célebre definición de Dante (en el De vulgari eloquentia), el volgare del sí es la lengua hablada en Italia, en contraste con los vulgares del oc y del oïl.

${ }^{5}$ Primero en la Raccolta aragonese (1473), encargada por Lorenzo de' Medici al filólogo de corte Agnolo Poliziano, una antología de la poesía en volgare: desde los poetas sicilianos de la corte de Federico II (1230-1250) hasta los de la corte del mismo Lorenzo, pasando por los llamados sículo-toscanos (Guittone, Bonagiunta), los stilnovisti (Guido Guinizzelli, Guido Cavalcanti, el Dante joven), Dante y Petrarca: en esta antología, símbolo de la política cultural de Lorenzo il Magnifico, se establece una tradición lírica áulica "italiana" en vulgar. Después, el clasicismo renacentista ratificará en cierta medida este canon, sin embargo privilegiará la imitación del modelo único: el Canzoniere de Petrarca y, en menor medida, el Boccaccio "trágico", es decir, los cuentos "serios" del Decameron. 
textualidad y adquiere su pleno significado en relación con el trasfondo cultural y literario contemporáneo. El resultado es una redefinición del género caballeresco.

En estudios recientes que analizan las relaciones del poeta con el ambiente cultural de Ferrara, en particular el de los humanistas latinos (Prandi, 2006; Savarese, 1984), emerge la importancia y persistencia de la formación humanista y neoplatónica latina de Ariosto y la necesidad de rastrear su influencia en el Furioso, superando la tradicional dicotomía entre las obras menores, influenciadas por la cultura humanista y el clima cultural de la época, y la obra maestra, desvinculada de todo contexto. La aportación de la cultura humanista se considera ahora en toda su complejidad: a la idea de un Ariosto imperturbable y sonriente, el "poeta de la armonía"6 y de un perfecto equilibrio entre tensiones y contratensiones ideológicas, de una síntesis perfecta y pacificada de la cultura precedente, se opone otra del Furioso como poema del conflicto (Padoan, 1974; Ascoli, 1987). Es por medio del conflicto - un conflicto vital y fecundo pone en marcha y va alimentando el mecanismo narrativo - que resuena la voz del autor, con su forma peculiar de estar al mismo tiempo dentro del texto y fuera de él. Y la representación de la locura de Orlando en términos erasmianos es de este conflicto el momento más alto y complejo, configurándose así como el microcosmos simbólico que encierra en sí el significado del macrocosmos del poema ariostesco.

Para entender cabalmente la relación de Ariosto con sus fuentes, el marco de referencia es la poética de la imitatio y de la variatio:

Antes del siglo XIX, cuando prevaleció una preferencia para la novedad y la originalidad, la habilidad de volver a narrar la misma historia de manera distinta era muy apreciada en la poesía. Inventio significaba recopilar materiales, no inventarlos. Se refería a encontrar, seleccionar de la masa de obras anteriores algo que, aunque ya tratado, el nuevo poeta transformaría en algo propio. Los mitos, las historias que contaban los poetas eran disponibles por definición (Javitch, 2005: 1).

El Furioso es, en este sentido, una verdadera "máquina tragagéneros": Ariosto "hace del clasicismo del Cinquecento [...] un instrumento artístico dúctil, capaz de anular las jerarquías de los niveles temáticos y estilísticos, que favorece la tendencia hedonista de la literatura renacentista recompensándola con una absoluta perfección formal" (Borsellino, 1973: 12). El clasicismo de Ariosto asumió una función de mediación para asimilar la cultura literaria de Ferrara a la cultura burguesa de la lengua vulgar florentina que alcanzó su definitiva canonización y codificación por obra de Pietro Bembo, e imponer, en línea con el proyecto bembiano, un modelo literario "nacional" (Borsellino, 1973: 11). En la última edición del Furioso, la de 1532, Ariosto se adhirió a la propuesta del clasicismo lingüístico de Bembo eliminando formas que se percibían como demasiado dialectales, en particular las del dialecto emiliano, además de los latinismos “crudos y pesados” (Binni, 1968: 303); esta adhesión se explica como una voluntad de

\footnotetext{
${ }^{6}$ Esta famosa definición fue acuñada por De Sanctis, 1954: 90-96, y retomada por Croce, 1961: 4-8.
} 
dar a su poema un carácter "nacional", con una lengua que pudiera ser reconocida y aceptada por todo el mundo literario italiano; sin embargo, la relación de Ariosto con el clasicismo del tiempo no es servil y acrítica, al rehusar rotundamente la propuesta bembiana de la necesidad de un modelo único a imitar para alcanzar la perfección formal.

Un moderno análisis de las fuentes de Ariosto precisa mostrar "cómo los artistas narrativos del Renacimiento renovaron el género popular del poema caballeresco a través de su imitación de la épica clásica" (Looney, 1996: 15). La cultura renacentista tiene una predisposición innata a citar y mezclar fuentes distintas, dándole un nuevo valor y significado dentro de su propio discurso para renovar un género típicamente medieval y adaptarlo a los nuevos gustos humanistas. Es la mezcla de elementos clásicos - tomados de la épica, del idilio pastoril, de la sátira, de la historia, de la comedia y la tragedia - con las contribuciones del humanismo renacentista y las demandas estéticas de la cultura popular lo que contribuye a crear un género nuevo adaptado a la cultura de la corte de Ferrara.

Por lo tanto, el objetivo de este estudio es el de presentar el episodio de la locura de Orlando marcando los elementos relevantes para aplicar la perspectiva que acabo de exponer. Esto implica considerar las fuentes humanistas como un filtro que interpreta la tradición clásica y medieval, con el trasfondo de los debates literarios de la época, como la Questione della lingua y la poética de la imitación. Asimismo, es fundamental tomar en cuenta la cultura —oral y escrita, de primera o de segunda mano- que circulaba efectivamente entre el público del Furioso, y que Ariosto podía por ende evocar implícita y explícitamente, confiando en que su intención fuera reconocida — por lo menos por parte de su público más culto.

Todo lo anterior nos impulsa a identificar y evaluar no sólo de las fuentes textuales explícitas — clásicas, medievales y humanistas — sino también las fuentes evocadas, que no se limitan a un verso o a una expresión lingüística precisa e identificable, sino que proyectan su luz y significado sobre todo un episodio. Por ejemplo, en la narración de la locura de Orlando, el episodio del amor entre Eneas y Dido (Virgilio, Aeneidos IV) y en particular el tema de la gruta, no está presente como una cita textual, sino como una evocación. ${ }^{7}$ Lo mismo se puede postular, como veremos, para Dante Inf. V, 82-142 (el canto de Paolo y Francesca, condenados por amor), que es una fuente temática y estilística al mismo tiempo con respecto a la caracterización de Amor y de su poder en la lamentación que representa el preludio a la locura de Orlando. Y en la narración de la de la furia homicida de Orlando me parece que se evoca la descripción homérica (Odisea IX, 187-265) de la manera en que Polifemo asesina y se come a los compañeros de Ulises. A partir de este tipo de análisis, el objetivo es el de avanzar hacia una primera propuesta de clasificación de las fuentes de

\footnotetext{
${ }^{7}$ En realidad encontramos una referencia explícita a este episodio en el c. XIX, oct. 35, cuando se narra el amor de Angélica y Medoro. Tal parece que en éste se anticipan algunos de los temas que se desarrollarán en el episodio de la locura de Orlando, por lo cual es preciso incluirlo en cierta medida en el análisis.
} 
Ariosto como de un caso paradigmático del Renacimiento, que refleje la complejidad de la cuestión, matizando y definiendo de manera más precisa el concepto mismo de fuente del humanismo en adelante.

La locura de Orlando caracteriza el poema desde su título y aparece como motivo dominante desde el proemio. El adjetivo furioso, que en italiano moderno significa "muy enojado", aquí significa "loco de atar" y se deriva del adjetivo latín furens, que aparece en el título de la tragedia de Séneca Hércules furens. Además, la locura de Orlando tiene una función paradigmática, volviéndose el símbolo, la representación extrema de una locura de amor universal que inclusive afecta al mismo poeta: "Dirò d'Orlando in un medesmo tratto / cosa non detta in prosa mai né in rima / ché per amor venne in furore e matto, / d'uom che sí saggio era stimato prima; / se da colei che tal quasi m'ha fatto, / che 'l poco ingegno ad or ad or mi lima, / me ne sarà però tanto concesso / che mi basti a a finir quanto ho promesso" (canto I, octava 2). Orlando es el caballero perfecto, el más fuerte, el más sabio y cristiano: es por eso que su locura asume el valor de una verdadera paradoja, desde el título: y en efecto la paradoja es una de las figuras retóricas prevalecientes en el poema ariostesco.

La narración del episodio que desencadena la locura de Orlando (cantos XXIIIXXIV) ocupa la parte central del Furioso $^{8}$ y ha sido identificada como un verdadero "parteaguas estructural" (Zatti, 1988: 8) del poema. Es el momento en el cual los varios hilos de la quête se enmarañan en un nudo general, en un total impasse, que culmina en el episodio de la Discordia (c. XXVII). ${ }^{9}$ Si la primera parte del poema había sido dominada por la quête, por la búsqueda de objetos y personas, la segunda parte, después de la locura de Orlando, tendrá un fuerte cambio narrativo y de escenarios. La quête se transforma, y de una búsqueda material se convierte en una búsqueda de conocimiento. Así, el movimiento narrativo se aleja del modelo épico y se vuelve más novelesco (Zatti, 1988: 4-7). Representa el lugar de convergencia de una multitud de hilos temáticos, gobernados por el entrelacement, y es, al mismo tiempo, el punto de cambio narrativo que parte en dos el poema (Zatti, 1988: 9). La catástrofe del protagonista es su fulcro; además, la historia de Orlando es el paradigma ejemplar más importante de todo el poema, y su locura — que da el título — representa el clímax.

Tanto el entrelacement como la bipartición son esquemas familiares para la épica, la chanson de geste y los libros de caballería, por lo que se han buscado los modelos estilísticos y estructurales del entrelacement - la técnica aédica sistematizada en Homero, retomada por Virgilio y los demás poetas épicos latinos y reelaborada en la Chanson de geste (Zatti, 1988; Del Corno Branca, 1973, 1992 y 1998; Tylus, 1988)-

\footnotetext{
${ }^{8}$ También encontramos referencias indirectas a la locura de Orlando en otros puntos del poema, como por ejemplo en el mencionado c. I, oct. 2, y en el c. XIX, oct. 33-42, donde se cuenta el amor de Angélica y Medoro anticipando varios de los temas presentes en los cantos XXIII-XXIV: detalles sobre sus amoríos en el bosque, el tema de la escritura y el objeto del reconocimiento, la historia y proveniencia de la pulsera, hasta llegar a su viaje de regreso hacia Catai y el encuentro de la pareja con un uom pazzo, quien los ataca como un cagnazzo. Además, hay dos narraciones de la locura del conde en el c. XXXI.

${ }^{9}$ Para una propuesta de análisis de la estructura del Furioso con un enfoque greimasiano, $c f$. Olsen, 2005.
} 
y de la bipartición - esquema típico de vidas de santos, chansons de geste y libros de caballería donde el punto de ruptura entre las dos partes era en general una catástrofe (en su sentido etimológico: la muerte, el descenso al Infierno, la caída en el pecado; $c f$. Ryding, 1971) - considerando que también la épica había sido reconceptualizada en modelos bipartitos en la Edad Media (cf., por ejemplo, el Roman d'Enéas, Zatti, 1988: 10), de los cuales la muerte de Roland en la Chanson homónima y la locura de Tristano, pero también la katábasis de Ulises y la de Eneas, son ejemplos relevantes (Zatti, 1988: 10).

Es preciso recopilar todas las fuentes temáticas y textuales de este episodio, estableciendo en un segundo momento de qué tipo de tradición (directa o indirecta; original o vulgarización; original o reelaboración crítica humanista, etcétera) proviene cada fuente, y qué peso tiene en el entramado textual.

A continuación, presentaré este episodio marcando en cada caso las fuentes textuales y las evocadas, en la perspectiva que acabo de definir.

Al final del canto XXIII (octava 100), Orlando llega vagando ${ }^{10}$ a un locus amoenus para descansar en la tarde calurosa y, mirando a su alrededor, lee los nombres de Angélica y Medoro juntos ("Angelica y Medor con cento nodi / legati insieme, e in cento lochi", oct. 103), tallados en todas las ramas y los arbustos a su alrededor. Orlando intenta convencerse de que se trata de otra Angélica, sin embargo reconoce perfectamente su letra; entonces, aun atormentado por la sospecha, quiere creer ("usando fraude a se medesmo", oct. 104) que el de Medoro sea un nombre ficticio que alude a él mismo, según la tradición cortés de mantener el amor en secreto, codificada por el De Amore y presente en la poesía provenzal, siciliana, del Stil Novo, y en la literatura caballeresca. En su incertidumbre, Orlando se parece a un pájaro, que se topa con una red o "liga" de muérdago: esta metáfora, que Ariosto retoma también en el incipit del canto siguiente (XXIV, oct. 1, v. 1, "amorosa pania"), evoca casi literalmente un símil ovidiano (Metamorfosis XI, 73-75: "utque suum laqueis, quos callidus abdidit auceps, / crus ubi commisit volucris sensitque teneri, / plangitur ac trepidans adstringit vincula motu"), que describe la misma situación (el pájaro capturado por el cazador) con una variatio (los lazos en Ovidio, la liga en Ariosto). Después, Orlando entra en una gruta cuyas paredes están cubiertas por los nombres de los dos amantes, escritos con carbón, con gis, y tallados con puntas de cuchillos ("qual con carbone, qual con gesso / e qual con punte di coltelli impresso", oct. 106). En la entrada de la gruta hay un poema escrito por Medoro en árabe, lengua que, como nos explica Ariosto, el conte entendía perfectamente y cuyo dominio lo había sacado de apuros muchas veces (oct. 110). Ariosto ofrece a sus lectores una traducción del poema de Medoro (oct. 108-110), que utiliza varios tópoi de la tradición epigramática clásica - aunque ninguno de ellos es una cita literal: más bien se evoca su atmósfera. El poema elogia la belleza del lugar, describe el gran deleite que su autor tuvo en la gruta al tener a Angé-

${ }^{10}$ El verbo ariostesco es errare, que denota los dos campos semánticos de "vagar" y "errar". 
lica desnuda en sus brazos, que es una cita casi literal de Boccaccio, Decameron, VIII, 7: "lei potere ignuda nelle braccia tenere" (cf. Furioso XXIII, oct. 108, v. 5: "spesso ne le mie braccia nuda giacque"), y finalmente pide a los transeúntes que respeten el lugar y le rueguen a los Dioses mantenerlo siempre puro e incontaminado.

Orlando lee una y otra vez el poema ("tre volte e quattro e sei lesse lo scritto", oct. 111), intentando en vano negar su existencia o autenticidad, quedando literalmente paralizado por el dolor, sin tener voz para quejarse ni lágrimas para llorar (oct. 111113), con una cita casi literal de Ovidio (Heroidas, XV, 110-112): "nec me flere diu, nec potuisse loqui / et lacrimae deerant oculis et verba palato, / adstrictum gelido frigore pectus erat" (Innamorati, 1997: 592). Orlando logra volver en sí y seguir dudando de lo que ve, al suponer que el autor del escrito haya sido alguien que quiera enlodar el nombre de Angélica o atormentar al mismo Orlando con el insoportable peso de los celos.

Reconfortándose un poco, Orlando monta su caballo y va a alojarse en el pueblo más cercano, con una cita casi literal de Virgilio (Éclogas I, 82): "Et iam procul villarum culmina fumant" (Innamorati, 1967: 594). En la habitación que le asignan, como en una alucinación, reaparecen los nombres de los dos amantes escritos en cada pared, en cada puerta, en cada ventana. El conde no puede dormir, por lo que el pastor, su anfitrión, para reconfortarlo, le cuenta la romántica historia de los dos amantes que se alojaron en su casa y que terminaron casándose allí mismo (oct. 118). La narración concluye con la exhibición de la recompensa que Angélica había dado al pastor: una pulsera, que el mismo Orlando le había regalado. Aquí me parece que se evocan elementos típicos de la tradición cuentística y del teatro clásico, en particular de la comedia terenciana, como el objeto de reconocimiento - la pulsera- y la figura de "el que desvela la verdad" - un deus ex machina o una persona común y corriente: en este caso, el pastor.

Esta conclusión fue el hacha que le quitó de tajo la cabeza a Orlando (oct. 121): el conde vuelve a acostarse, pero se levanta de golpe - como un pastor que ve a una serpiente en el pasto donde está recostado a punto de dormir, un símil virgiliano casi literal: "improuisum aspris ueluti qui sentibus anguem / pressit humi nitens trepidusque repente refugit / attollentem iras et caerula colla tumentem" (Virgilio, Aeneidos, II: 378-380, cit. por Innamorati, 1997: 596) — al darse cuenta que los dos amantes yacieron juntos justo en esa misma cama, y vuelve al bosque donde finalmente puede abandonarse al llanto; pasa días y noches errando en la selva, llorando y gritando sin parar, hasta prorrumpir en un lamento desesperado, una elegía dentro del poema, tres octavas (XXIII, oct. 125-127) que parecen el controcanto al radiante epigrama de Medoro. En esta lamentación, ${ }^{11}$ que representa el preludio de la explosión total de su furia destructora (XXIII, oct. 126-128), Rájna (1900: 349-350, cit. en Borsellino, 1973: 115) reconoció como fuente temática para la oct. 128 el epigrama en latín Ad amorem

\footnotetext{
${ }^{11}$ Sobre la cual, cf. también Bausi, 1996.
} 
del humanista del siglo XV Michele Marullo: "Non sum non ego quem putas Marullum. / Iam pridem occidit ille nec superstes / carae dissidium tulit Neaerae" (Epigrammata, III, XLIV: 4- $\left.6^{12}\right)$. Me parece que ésta no es sólo una fuente temática, sino también estilística, ya que Ariosto retoma la negación enfática de Marullo: $c f$. Furioso XXIII 128 , "Non son, non son io quel che paio in viso: / quel ch'era Orlando è morto ed è sotterra; / la sua donna ingratissima l'ha ucciso". Además, me parece reconocer en las tres octavas de la lamentación otros aspectos relacionados con este mismo epigrama. Primero se observa una amplificación de la negación de Marullo "Non sum non ego", referida primero a las lágrimas y después a los suspiros y sólo en la tercera octava (la citada oct. 128) a la identidad de Orlando: "Queste non son più lacrime, che fuore / stillo dagli occhi con sí larga vena" (Furioso XXIII, oct. 126, vv. 1-2) y "Questi ch'indizio fan dei miei dolori / sospir non sono, né i sospir son tali" (Furioso XXIII, oct. 127, vv. 1-2). La identificación de las lágrimas del amante con su propia sangre, presente en el mismo epigrama de Marullo ("Si nescis meus est Neaera sanguis / istos quem lacrimae rigat ocellos", Epigrammata, III, XLIV, vv. 15-16), se retoma en el principio de la lamentación de Orlando con una amplia variatio: Orlando no llora sangre sino su propio "humor vital", que, huyendo por sus ojos será la causa de su muerte, y al mismo tiempo el único remedio para su dolor: "non suppliron le lagrime al dolore: / finîr, ch'a mezzo era il dolore a pena. / Dal fuoco spinto ora il vitale umore / fugge per quella via che agli occhi il mena; / et è quel che si versa, e tratta insieme / e 'l dolore e la vita all'ore estreme" (Furioso, oct. 126, vv. 3-8). Ariosto entonces evoca sutilmente el epigrama de Marullo en las primeras dos octavas de la lamentación y lo cita casi textualmente sólo en la última (por medio de la anáfora "non son, non son io"), pero desde la primera octava de la lamentación anticipa el tema de las lágrimas que llevan a la muerte. Mientras Marullo nombra a Neera como resposnsable de su muerte, Orlando se refiere a Angélica con una perífrasis: "la sua donna ingratissima l'ha ucciso" (Furioso XXIII, oct. 128, v. 3).

En la segunda octava de esta lamentación, la anáfora de "Amor" en principio de versos alternados evoca un notable pasaje de Dante, Inferno, V, 96-107: "Amor, ch'al cor gentil ratto s'apprende / prese costui della bella persona / che mi fu tolta: e il modo ancor m'offende. / Amor ch'a nullo amato amar perdona / mi prese del costui piacer sí forte / che, come vedi, ancor non m'abbandona. / Amor condusse noi ad una morte / Caina attende chi vita ci spense" (cf. Furioso XXIII, oct. 127, vv. 5-8: "Amor che m'arde il cor, fa questo vento, / mentre dibatte intorno al fuoco l'ali. / Amor, con che miracolo lo fai, / che 'n fuoco il tenghi e nol consumi mai?"). Además de la anáfora de "Amor ch" y "Amor" en principio de verso, ambos poetas presentan una

\footnotetext{
${ }^{12}$ El texto de los Epigrammata de Michele Marullo no fue fácil de encontrar. Lo encontré en la edición digitalizada de un incunabulum de 1497, cuyo colofón reporto: "Impressit Florentiae Societas Colubris VI Kal. Mense Decembris MCCCCLXXXXVII". La obra está disponible en la página web de la biblioteca digitalizada de la Universidad de Sevilla: http://fondotesis.us.es/fondos/libros/221/195/hymni-et-epigrammata/, consultada el 24 de abril de 2011. El epigrama III, XLIV, se encuentra en las pp. 88-89 de la digitalización.
} 
prosopopeya del amor, descrito como una persona. Sin embargo, mientras Dante narra de dos condenados por amor que siguen juntos por la eternidad gracias al poder del amor, Ariosto utiliza esta evocación en el momento en que Orlando llora por la traición de su ingrata mujer: la evocación asume matices irónicos a través de la interxtextualidad. Y finalmente cabe observar que en este mismo canto, pocos versos antes, Dante mencione a Dido (Inferno V, 85, "cotali uscîr della schiera ov'è Dido") y su triste historia de amor (Virgilio, Aeneidos es uno de los subtextos evocados no textualmente por Ariosto a través del tema de la gruta, que mencioné supra).

Finalmente, el destino lleva a Orlando a su lugar de partida: el locus amoenus, la fuente, la gruta. Al ver su deshonra escrita en la piedra, no hay nada en Orlando que no sea "odio, rabia, ira y locura" (XXIII, oct. 129, v. 7), y con su fuerza sobrehumana empieza a destruir la inscripción junto con todo el espacio sagrado del amor de Medoro y Angélica: despedaza las piedras y cada árbol y arbusto que lleve sus nombres, y avienta todo a la fuente, enturbiándola para siempre. Después, cansado, yace en la tierra por tres días y tres noches, mientras su tremendo dolor no deja de crecer. Al cuarto día, ya totalmente loco, se quita de encima armadura, armas y vestimenta quedando totalmente desnudo, y empieza a arrancar árboles como si fueran plantas de hinojo o eneldo (este símil se encuentra en Boiardo, Orlando innamorato, III, oct. 29, v. 4: "Stirpar le quercie a guisa di finocchi", cit. por Innamorati 1997: 598).

El incipit del canto XXIV marca - como es costumbre en Ariosto - una pausa en la narración; el poeta reflexiona en primera persona sobre la locura de amor y sobre los que persisten en ella, incluyéndose dentro de esta categoría. En la oct. 1 se cita — con variatio - a Poliziano, Stanze, I, oct. 13, vv. 5-6 (Innamorati, 1997: 600), en la definición del amor como insania, sólo reconocible por lo sabios: "[...] Amore / è dolce insania a chi più acuto scorge" (cf. Furioso XXIV, oct. 1, vv. 3-4: "che non è insomma amor se non insania / a giudizio dei savi universale"). En los vv. 7-8 de la misma octava se cita a Bembo, Asolani, I, XXXIII: "En tanto me riscuoto e veggio expresso / che per cercar altrui perdo me stesso" (Innamorati, 1997: 600), en la descripción paradójica del amor como pérdida de uno mismo por querer a otra persona, utilizando exactamente las mismas palabras en la rima: espresso / stesso, y llevando a cabo una variatio: de la primera persona me de Bembo a la tercera se de Ariosto. Además, hay una cita casi literal de Petrarca, Rime XCIX, 12-4 (Innamorati, 1997: 600-601): "Ben si può dire a me: - Frate, tu vai / mostrando altrui la via dove sovente / fosti smarrito..." (cf. Furioso XXIV, oct. 2, vv. 1-2: "Ben mi si potría dir: -Frate, tu vai / l'altrui mostrando, e non vedi il tuo fallo").

En la oct. 4 se resume la narración de la locura de Orlando, describiendo la matanza que el loco Orlando hace de los pastores y campesinos, quienes intentan detenerlo con un "villanesco assalto" (XXIV, oct. 8, v. 8). Aquí encontré una evidente evocación de textos satíricos sobre los campesinos que circulaban en el Renacimiento, en particular la anónima Sferza dei Villani, 2, 1-4: "E come d'Ecco la voce rimbomba / in ville in valle, dov'altri lo chiama / Eco faccia i miei versi eguali a tromba, / che risuoni per tutto la lor fama" (cf. Furioso XXIII, oct. 8, vv. 1-4: "Già potreste sentir come ribombe 
/ l'altro rumor ne le propinque ville / d'urli, e di corni, rusticane trombe, / e più spesso che d'altro, il son di squille").

Después, se describe la vida salvaje que el conde lleva vagando como una fiera por toda la región, atacando los caseríos, cazando y comiendo animales crudos, con todo y piel. La representación de la locura como regreso a la condición de animal salvaje evoca la locura de Tristán y Lancelot. La mención de la violencia en contra de caballos y bueyes (XXIV, oct. 7) — que se volverá, como veremos, un leitmotiv de la locura de Orlando- evoca el Ajax de Sófocles. ${ }^{13}$ El rasgo que evoca el Hercules Furens de Séneca es la violencia extrema que caracteriza la locura de Hércules y de Orlando. Ambos son héroes, personajes extraordinarios en todas sus manifestaciones, y la locura no es una excepción; además, Orlando - como Hércules, pero también como Aquiles - se describe como invulnerable: "era a periglio di morir Orlando / se fosse di morir stato capace" (XXIV, oct. 11, vv. 1-2) y "la pelle trovò dura come osso / anzi via più ch'acciar; ch'Orlando nato / impenetrabile era et affatato" (XIX, oct. 62, vv. 6-8). Una última fuente que Ariosto evoca en la descripción de la violencia destructiva de Orlando, me parecen - como ya mencioné supra - los pasajes del libro IX de la Odisea ${ }^{14}$ donde se describe la violencia de Polifemo.

Finalmente, en la oct. 14, Orlando llega a un puente sobre un gran río, y allí Ariosto lo deja, para narrar las aventuras de otros personajes.

La prosecución de las aventuras del pazzo conte se encuentra en el canto XXIX, oct. 40, donde Orlando lucha con Rodomonte, quien, con su proverbial arrogancia, intenta impedirle cruzar el puente hasta que ambos se caen al río, y Orlando se aleja nadando sin fijarse más en su contrincante (oct. 46-48). Quien reconoce al conde es una dama, Fiordiligi, que se queda asombrada ante el espectáculo del conde, loco y desnudo ("de la follia che così nudo il mena", oct. 45): a partir de este momento, la noticia de la locura de Orlando se difunde entre los cristianos (y se narrará en XXXI, oct. 42-48 y 62-63). Después, Ariosto narra el destructivo encuentro del loco con dos pobres leñadores y su asno, y su llegada a la orilla del mar cerca de Tarragona, en España, donde decide repararse del sol enterrándose en la arena (oct. 57-58). Pasan por allí Angélica y Medoro, a punto de zarpar hacia Catai: Angélica se aterroriza y grita al ver a Orlando, a quien por supuesto no reconoce, por estar absolutamente diferente de lo que era (oct. 58-60).

En la descripción que Ariosto hace de Orlando reconocemos todos los rasgos del hombre desesperado por amor descrito por Boccaccio, Filocolo, III, 36, 2 (Innamorati, 1967: 748): "il vide nel viso diventato bruno, e gli occhi rientrati in dentro appena si vedeano. Ciascuno osso pingeva in fuori la raggrinzata pelle, e i capelli con disordinato rabbuffamento occupavano parte del dolente viso e similmente la barba grande era divenuta rigida e attorta" ( $c f$. Furioso XXIX, oct. 60, vv. 1-4: "Quasi ascosi avea gli occhi ne la testa / la faccia macra, e come un osso asciutta, / la chioma rabbuffata,

${ }^{13}$ Cuya editio princeps fue la de Manuzio, publicada entre 1502 y 1504 (Reynolds-Wilson, 1986: 152).

${ }^{14}$ Conocidos seguramente en traducción o por tradición indirecta. 
orrida e mesta, / la barba folta, spaventosa e brutta"). Al loco conde "le apetece" ("ne venne immantinente giotto", oct. 61: el adjetivo "giotto", "ghiotto" en italiano moderno, significa "goloso") la bonita mujer, cuyo recuerdo ya no guarda, y se levanta para apresarla. Medoro lo ataca desde atrás para cortarle la cabeza, pero Orlando, invulnerable, sólo percibe un golpecito en la espalda, y, al voltearse, mata por accidente al caballo del esposo de Angélica (oct. 62-63), lanzándose a perseguirla. Angélica se pone en la boca el anillo mágico de la invisibilidad y desaparece al instante (oct. 64), pero al mismo tiempo es desarzonada por su caballo, y por poco choca con Orlando, cayéndose indecorosamente en la arena con las piernas abiertas (oct. 65-66). Con esta embarazosa caída, invisible para Orlando y Medoro pero no para los lectores del Furioso, Angélica sale para siempre de la escena del poema. Orlando, por su parte, ni siquiera se da cuenta de la desaparición de Angélica y sigue corriendo detrás de su yegua desbocada, que finalmente captura y trata con el mismo júbilo con el cual se trataría a una doncella (oct. 67-68), la monta por millas y millas sin descanso ni comida, hasta que el pobre animal se quiebra una pata; Orlando primero la carga en sus brazos, pero, cansado, decide "ayudarla" arrastrándola por una pata, y obviamente la yegua muere sufriendo atrozmente, pero Orlando no deja de llevar consigo su cadáver (oct. 69-72). Ariosto comenta, para terminar el canto, que lo mismo hubiera hecho con Angélica y que esto se ameritarían todas las mujeres por ingratas (oct. 73-74).

En el canto siguiente, el XXX, después de una disculpa del poeta por cuanto fue expresado al final del canto anterior (oct. 1-4), se narra cómo Orlando, después de errar muchos días llevando a la yegua muerta, cruza un río donde éste desemboca al mar e intenta canjear el cadáver de la yegua con el caballo de un pastor, quien se ríe de él. Orlando lo mata y se lleva su caballo, que pronto tendrá el mismo destino de la yegua: de esta forma, sigue consiguiendo nuevas cabalgaduras. Después de saquear y destruir la ciudad de Málaga, Orlando llega al estrecho de Gibraltar (oct. 4-10), donde, a falta de un navío que quiera detener su curso para llevar consigo a un loco como él, se mete al agua con todo y caballo, que naturalmente se ahoga; pero Orlando sigue nadando varios días hasta llegar a la vista de la ribera africana, hormigueante de hombres armados (oct. 11-15).

La siguiente aparición del loco coincidirá con su encuentro con Astolfo — quien acaba de regresar del mundo de la Luna, donde recuperó la ampolla que contiene la cordura de Orlando- y con otros paladines cristianos, quienes lograrán someterlo y darle a inhalar su cordura. Finalmente, Orlando regresa en sí, avergonzado de su desnudez y profundamente apenado por su error (XXXIX, oct. 35-38 y 44-60). En la oct. 60 se alude a un episodio de Virgilio, Éclogas, VI, 24, donde Sileno, tras haberse quedado dormido en estado de ebriedad, al despertar amarrado por unos jóvenes les pide que lo suelten: "Solvite me, pueri; satis est potuisse videri" ( $c f$. Furioso XXXIX, 60, 1-3: "Poi disse, come già disse Sileno / a quei che lo legâr nel cavo speco / — Solvite me - con viso sí sereno"). Esta cita — cuyo aspecto explícito es el nombre de Sileno y la apóstrofe en latín: "Solvite me" — sugiere, a quien conoce el episodio, una analogía entre la locura por amor de Orlando y la ebriedad de Sileno, y en ambos 
episodios hay una referencia (indirecta en Virgilio: "ya es suficiente lo que vieron" y directa en Ariosto, oct. 59, v. 7: "si maraviglia che nudo si vede") a la vergüenza por la propia desnudez, que es un símbolo de la "caída". La referencia a la premura de los paladines para cubrir con sus vestidos la desnudez de Orlando evoca el acto de los hijos de Noé, quienes cubren la desnudez del padre ebrio: "20 coepitque Noe vir agricola exercere terram et plantavit vineam 21 bibensque vinum inebriatus est et nudatus in tabernaculo suo 22 quod cum vidisset Ham pater Chanaan verenda scilicet patris sui esse nuda nuntiavit duobus fratribus suis foras 23 at vero Sem et Iafeth pallium inposuerunt umeris suis et incedentes retrorsum operuerunt verecunda patris sui faciesque eorum aversae erant et patris virilia non viderunt" (Vulgata, Génesis, 9: 20-23). La fuente clásica se entrelaza con la cristiana, en este excelente ejemplo del tratamiento ariostesco de las fuentes.

Finalmente, Orlando se encuentra totalmente cuerdo, absolutamente libre de amor, por lo que se compromete a obtener de nuevo todo lo que el amor le ha quitado.

En conclusión, a nivel de citas textuales, en particular de tópoi, en el episodio de la locura de Orlando se entrelazan fuentes clásicas, en particular Virgilio y Ovidio, y en menor medida Horacio y Catulo, con fuentes vulgares como Dante, Petrarca, Boccaccio, Poliziano, Boiardo y Bembo. Estas últimas parecen tener en general mayor alcance, no limitarse puramente a tópoi literarios sino referirse a conceptos significativos para toda la narración, como el caso del amor como pérdida de sí mismo (Petrarca). No es casual que el incipit del canto XXIV —el espacio de reflexión de Ariosto sobre la locura - cite casi literalmente a tres de ellas; ni tampoco es un caso que se cite a un refinado autor humanista latino como es Michele Marullo, en una etapa crucial de la locura: la lamentación de Orlando, al final del canto anterior (XXII, oct. 126-128).

Por otro lado, el mismo Rájna (1900: 396 y 400, cit. en la edición del Furioso de Innamorati, 1967: 602) identifica relaciones textuales entre la descripción de la locura de Orlando y la de Tristán y otros paladines en el Chevalier au Lion o en el Tristan, en particular en sus rasgos de regreso a una condición salvaje, más similar a la de una fiera que a un ser humano. Innamorati (1967: 748) reconoce también a Boccaccio como fuente textual para la descripción de los rasgos físicos del loco Orlando.

Una fuente peculiar que no encontré mencionada en la bibliografía consultada y que pude individuar por mi cuenta es la Sferza dei villani: se trata de un texto anónimo, de nivel medio-bajo pero producido seguramente en ámbito culto y cortesano, donde se desarrolla el tópos - muy característico de la literatura burguesa italiana, desde la Edad Comunal (siglo XIII) hasta todo el siglo XVII- de la bestialidad de los campesinos (villani). En los siglos XV y XVI circuló mucho material —oral y escrito- sobre este tema (cf. la antología de Merlini de 1894).

En la nueva perspectiva intertextual, las fuentes evocadas asumen una mayor importancia, pues aunque no estén siempre presentes como cita textual, proyectan su sombra en todo el episodio: lo que se evoca no es sólo el tema sino también el tono, el estilo, aspectos formales, alguna idea que estaba detrás del texto o algún valor simbólico que el texto en cuestión revistiera dentro de la cultura contemporánea a Ariosto. 
Éste es el caso del amor como locura del cual los sabios deben abstenerse (Poliziano, Petrarca); de la fenomenología de la locura como regreso a la condición salvaje (Lancelot, Tristán) y como extrema violencia (Sófocles y Séneca); de la vergüenza por la desnudez como resultado de una pérdida del control (Virgilio, pero también la Vulgata) y de la representación de los campesinos proverbialmente opuestos a los pastores, que habían sido celebrados en la Arcadia de Sannazaro basada en la idealización de la vida pastoril que es el leitmotiv de idilios y éclogas.

Entre las fuentes evocadas en este episodio, la de mayor alcance, que proyecta su sombra en toda la narración, es probablemente el Encomium Morias de Erasmo, que constituye, en las palabras de Borsellino (1973: 109), quizá la clave ideológica más segura para abarcar todo entero el significado del poema ariostesco... La locura que Erasmo exalta es el "iocundus quidam mentis error" que libera el alma de las angustiosas preocupaciones y lo colma de gozo... Este error placentero no necesita curación, sin embargo el otro "insaniae genus" del cual hablaba Erasmo, el que las Furias infundían en el corazón humano como deseo de guerra, sed de dinero, "vel dedecorosum ac nefarium amorem", es un furor funesto, del cual es necesario protegerse. Pero también para el sabio es difícil sustraerse a la locura de amor. Orlando, el más "intelectual" de los caballeros, es la víctima designada de un incontenible proceso de enajenación, desde el oscuro dolor de la infelicidad consciente hasta la explosión brutal de la demencia salvaje.

Ésta es una fuente evocada con la intención precisa de que su lector modelo ${ }^{15}$ la reconociera; es por eso que este tipo de fuentes pueden tener un peso aun mayor que ciertas fuentes textuales - literales o quasi literales, pero de alcance limitado - en la interpretación del texto.

Finalmente, me interesa observar que en la literatura sobre las fuentes del Furioso encontré poca atención ${ }^{16}$ a un tema que me parece digno de una observación más cuidadosa: el de la profunda ambigüedad de la escritura, su poder casi alquímico y su papel determinante en el progresivo enloquecimiento de Orlando. Es preciso enfocarse en el análisis de este tema, en particular en la búsqueda de sus fuentes en el sentido amplio definido arriba, para mostrar su exacto valor dentro de todo el episodio y el significado que asume en la poética ariostesca, rastreando sus fuentes. Una apología del poder destructivo de la pluma se encuentra en Boccaccio, Decameron, VIII, 7, donde se cuenta la tremenda venganza de un joven con estudios académicos (scolare) en contra de una mujer que le había jugado una mala pasada. En otro cuento del Decameron (IX, 5) se presenta el tema del poder mágico de la palabra escrita: Calandrino seduce a una mujer tocándole el cuerpo con una carta (brieve), que hace que la mujer se le entregue al instante.

Es importante dedicar una atención especial a este tipo de fuentes, para contribuir a encontrar criterios más precisos de distinción y jerarquización entre las fuentes del

\footnotetext{
${ }^{15}$ Para la noción de lector modelo, $c f$. Eco, 1994: 11-13.

${ }^{16}$ Con la excepción de Millicent, 1993, quien lo aborda desde un enfoque semiótico.
} 
Furioso y aportar elementos generales para aclarar la relación de los autores renacentistas con sus lecturas, con las lecturas de su público y en general con el ambiente cultural de producción y consumo de las obras mismas.

\section{Obras citadas}

ArIosto, Ludovico. 1967. Opere. A cargo de Giuliano Innamorati. Bolonia: Zanichelli.

1976. Orlando furioso. A c. de Cesare Segre. Milán: Mondadori.

AsCOLI, Albert Russell. 1987. Ariosto's bitter harmony: crisis and evasion in the Italian Renaissance. Princeton, N. J.: Princeton University Press.

BAUSI, Francesco. 1996. "L' 'epigramma' di Medoro e altre note ariostesche". Filologia Antica e Moderna, 10. 29-58.

BINNI, Walter. 1968. Ludovico Ariosto. Turín: ERI.

Borsellino, Nino. 1973. Ludovico Ariosto. Roma / Bari: Laterza.

Croce, Benedetto. 1961. Ariosto, Shakespeare, Corneille. Bari: Laterza.

DE SANCTIS, Francesco. 1954. La poesia cavalleresca e scritti vari. Bari: Laterza.

Del CoRno Brianco, Daniela. 1973. L'“Orlando furioso” e il romanzo cavalleresco medievale. Florencia: Olschki.

1992. "Tradizione italiana dei testi arturiani. Nota sobre Lancelot". Medioevo Romanzo, XVII. 215-50.

1998. "Franceschi romanzi. Copisti, lettori, biblioteche". Tristano e Lancillotto in Italia. Studi di letteratura arturiana. Ravena: Longo. 13-48.

ECO, Umberto. 1994. Sei passeggiate nei boschi narrativi. Milán: Bompiani.

FORNI, Giorgio. 2006. “Ariosto e l'ironia”. Lettere italiane, LVIII 2. 208-223.

Gulizia, Stefano. 2008. "L'Arcadia sulla luna: un'inversione pastorale nell'Orlando furioso". MLN, 123-1. 160-178.

JaVITCH, Daniel. 2005. "The poetics of Variatio in Orlando Furioso". Modern Language Quarterly, 66.1. 1-19.

LoONEY, Dennis. 1996. Compromising the Classics: Romance Epic Narrative in the Italian Renaissance. Detroit: Wayne State University Press.

MC CARTHY, I. 2009. “Ariosto the lunar traveller". The Modern Language Review, 104.1. 71-84.

MerLInI, Domenico, ed. 1894. Satira contro il villano. Turín: Loescher.

PADOAN, Giorgio. 1974. "L'Orlando Furioso e la crisi del Rinascimento". Ariosto 1974 in America. Ed. Aldo ScAGLIONE. Ravena: Longo. 1-29.

Prandi, Stefano. 2006. "Premesse umanistiche del Furioso: Ariosto, Calcagnini e il silenzio (O.F. XIV, 78-97)". Lettere italiane, LVIII, 1. 3-32.

RÁJNA, Pio. 1900. 2a. ed. Le fonti dell"“Orlando furioso”. Florencia: Sansoni. (Reimpreso por la misma editorial en 1975.) 
REYNOLDS, Leighton D. y Nigel G. WILSOND. 1986². Copistas y filólogos. Madrid: Gredos.

Ryding, William W. 1971. Structures in medieval Narrative. La Haya / París: Mouton.

SAVARESE, Gennaro. 1984. "Il progetto del poema tra Marsilio Ficino ed 'adescatrici galliche". Il "Furioso" e la cultura del Rinascimento. Roma: Bulzoni. 15-37.

Segre, Cesare. 1965. "Nel mondo della luna ovvero L. B. Alberti e Ariosto". Studi in onore di Alfredo Schiaffini II. Ed. Ettore PARATORE. Roma: Edizioni dell'Ateneo. 1025-1033.

1966. "Un repertorio linguistico e stilistico dell'Ariosto: la Commedia". Esperienze ariostesche. Pisa: Nistri-Lischi. 45-50.

. 1990a. "Pio Rájna: le fonti e l'arte dell'Orlando furioso". Strumenti Critici, v 64. 315-327.

1990b. Fuori del mondo. I modelli nella follia e nelle immagini dell'aldilà. Turín: Einaudi.

Tylus, Jane. 1988. "The Curse of Babel: The Orlando Furioso and Epic (Mis) Appropriation". MLN, 103. 154-171.

ZATTI, Sergio. 1988. "L'inchiesta, e alcune considerazioni sulla forma del Furioso". MLN, 103. 1-30. 